\section{Factors associated with satisfaction with pediatric emergency department services in Korea: analysis of Korea Health Panel Data 2010 to 2012}

\author{
Kyeong Jae Lee', Min Joung Kim², Joon Min Park', Kyung Hwan Kim', \\ Junseok Park', Dong Wun Shin ${ }^{1}$, Hoon Kim', Woochan Jeon', \\ Hyunjong Kim ${ }^{1}$
}

'Department of Emergency Medicine, Inje University Ilsan Paik Hospital, Goyang, Korea

${ }^{2}$ Department of Emergency Medicine, Yonsei University College of Medicine, Seoul, Korea

Objective We aimed to investigate the factors related to satisfaction with the pediatric emergency department service in Korea.

Methods This study examined data from the Korea Health Panel Data from 2010 to 2012. Pediatric patients who visited the emergency department at least once between 2010 and 2012 in Korea were included. Data were collected on patient satisfaction with the emergency department service, and factors related to the patient characteristics, emergency department service process, and medical institution. We compared the dissatisfied and satisfied groups, and calculated the odds ratios for satisfaction according to each variable.

Results A total of 1,505 emergency department visits from 947 pediatric patients during the 3 -year period were analyzed. We estimated that about 79.5\% of patients in the population were satisfied. The odds of expressing satisfaction were higher among males than in females, and among patients who were hospitalized after emergency department treatment compared to those who were transferred to another hospital. Conversely, the odds of expressing satisfaction were lower among patients who had a chronic disease, a financial source other than National Health Insurance, experienced hospitalization within 1 year.

Conclusion Our study results might be helpful for establishing a satisfactory pediatric emergency medical service system. In the future, further prospective studies evaluating the causal relationships between the relevant factors and patient satisfaction are warranted.

Keywords Patient satisfaction; Emergency medical services; Pediatrics; Parents
elSSN: 2383-4625

Received: 17 July 2017

Revised: 23 August 2017

Accepted: 11 September 2017

Correspondence to: Joon Min Park Department of Emergency Medicine, Inje University Ilsan Paik Hospital, 170 Juhwa-ro, Ilsanseo-gu, Goyang 10380, Korea

E-mail: aero7@outlook.kr

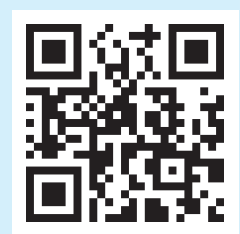

How to cite this article:

Lee KJ, Kim MJ, Park JM, Kim KH, Park J, Shin DW, Kim H, Jeon W, Kim H. Factors associated with satisfaction with pediatric emergency department services in Korea: analysis of Korea Health Panel Data 2010 to 2012. Clin Exp Emerg Med 2018;5(3):156164.

This is an Open Access article distributed under the terms of the Creative Commons Attribution Non-Commercial License (http:// creativecommons.org/licenses/by-nc/4.0/). 


Capsule
Wuat is already known
Factors related to the emergency department (ED) service process, such as the characteristics of human resources, the
ED treatment process, and the ED treatment space, are known to be related to the satisfaction of pediatric patients.
$\begin{aligned} & \text { What is new in the current study } \\ & \text { Various factors such as sex, presence of chronic disease, presence of financial funding other than National Health In- } \\ & \text { surance, hospitalization within a year, were found to be related to the satisfaction of pediatric patients. }\end{aligned}$

\section{INTRODUCTION}

The emergency department (ED) plays an important role as the primary entry route for patients who require acute management or hospitalization. Moreover, as many patients' first and only experience with hospital services involves visiting the ED, the ED may be an important determinant of the reputation of a hospital. ' In a report by the Korea National Emergency Medical Center, 203 out of every 1,000 people visited the ED in 2014. ${ }^{2}$ In the future, the demand for ED services is expected to increase as society ages and life patterns change, including more frequent participation in outdoor activities or expanded residential zones as a result of transportation development, the latter of which might lead to more patients with acute disease or injuries.

Pediatric patients comprise a significant proportion of all ED patients. Indeed, such patients accounted for $31.2 \%$ of all ED visits in Korea in one previous study. ${ }^{3}$ Pediatric ED patients differ markedly from adult ED patients not only in regard to anatomical and physiological characteristics, but also in various factors such as the reason for visits, injury or disease severity, and the presence of chronic disease. ${ }^{4,5}$ For example, the proportion of pediatric patients who need intensive care or admission due to severe injury is relatively low compared to that of adult patients. Considering these characteristics, the ideal facility criteria, pediatric ED equipment, and human resources have been investigated in some countries..$^{6-8}$

Similarly, it is necessary to investigate pediatric patient satisfaction with ED services separately from that of adult patients, which could increase the meaning of these results, owing to the following reasons: it can be a useful indicator of the quality of ED services, as healthcare can be considered a kind of service industry $^{9}$; it is closely related to the patients' adherence to the physicians' discharge instructions and to the patients' confidence in the hospital ${ }^{10,11}$; and finally, it marks an effort to improve ED ser- vices by considering ED patient satisfaction to enable the construction of a desirable emergency medical system.

Nevertheless, only a few, small studies investigating pediatric patient satisfaction have been conducted globally. ${ }^{12-15}$ In Korea, Moon and Kim $^{16}$ assessed patient satisfaction with nursing services in 2 metropolitan EDs. Jang et al. ${ }^{17}$ surveyed parental satisfaction using a questionnaire; however, the study population was not representative of the nationwide population. To the best of our knowledge, no study has assessed pediatric ED patient satisfaction with a representative sample of the Korean population. Therefore, in the present study, we assessed pediatric ED patient satisfaction and the related factors using national panel data.

\section{METHODS}

\section{Study design}

This study was a secondary analysis of the Korea Health Panel Data (KHPD) version 1.1 and was conducted after obtaining permission from the institutional review board of Inje University IIsan Paik Hospital (2017-03-005). The Korea Health Panel Data is an official statistical investigation approved by the government that has been conducted annually since 2008 by the National Health Insurance Service and Korea Institute for Health and Social Affairs. This investigation aimed to produce representative statistics regarding medical service use, medical expenditures, and financial sources. The sampling frame was 90\% of the national population investigated in the 2005 census of Korea, and 2 steps of probability proportionate stratified cluster sampling were conducted. The stratification variables included 16 metropolitan cities and provinces, and 2 towns. First, the sample clusters were extracted by region, and then the sample households were extracted from these. Lastly, family members from the sample households became the Korea Health Panel. The survey included a selfreport questionnaire and in-person interviews with trained inves- 
tigators; receipts for medical charges and prescriptions were referenced to support the information about the use of medical services provided by the household members. The survey was completed by the parents of most of the pediatric patients (including for all who could not yet read). Although most surveys were conducted within 1 year, the exact time gap between medical service use and survey completion was not available.

We included pediatric patients who used the emergency medical service at least once between 2010 and 2012. To select cases that met the inclusion criteria, we first merged the datasets for the household members' characteristics and ED visits. Then, pediatric household members (preschoolers, elementary school students, middle school students, or high school students) were selected. When a household member visited the ED more than once in a 1-year period, each visit was considered an independent sample case.

\section{Data collection}

Satisfaction with the ED services was the variable of major concern in this study. In the survey, the following question about each ED visit was asked in order to rate the patient satisfaction: "Overall, how satisfied were you with the emergency department visit?" The KHPD originally rated satisfaction using four responses (very dissatisfied, dissatisfied, satisfied, and very satisfied). We created a binary variable for satisfaction by converting the responses into "dissatisfied" or "satisfied" to assess the association with the following variables: patient characteristics (sex, education level as an indicator of age group, presence of a chronic disease [defined as a continuation of the same symptoms for more than 3 months], disability, medical insurance type, presence of a source of payment for medical costs other than National Health Insurance [NHI], household income [quintile], hospitalization or outpatient clinic visit within 1 year, and total ED visits), variables related to ED services (reason for the ED visit, time of ED arrival, delay in ED arrival, length of stay in the ED, transportation to the ED, type of medical services provided, discharge after ED treatment, and medical costs paid), and variables related to the medical institution (ownership and size of the hospital).

\section{Statistical analysis}

First, we estimated the population characteristics of the independent variables by applying the population weights to the sample data. Then, we divided the included sample cases for the 3 years into 2 groups (satisfied and dissatisfied) and compared the characteristics of the 2 groups by applying the sample weights to the sample data. Continuous variables are presented as the means and standard deviations, and categorical variables are presented as numbers and percentages. Differences between the 2 groups with regard to variables of interest were compared using the independent t-test for continuous variables and the chi-square test for categorical variables. We categorized transportation methods into a binary variable in this step: the use of ambulances versus other means of transportation. Finally, we investigated the associations between the variables that differed significantly between the 2 groups and patient satisfaction. Unadjusted and adjusted odds ratios (ORs) for satisfaction were obtained by simple and multiple logistic regression analyses, respectively; the multivariate analysis was adjusted for the variables that differed significantly in the univariate analysis. We considered P-values of less than 0.05 to be statistically significant. The statistical analysis was conducted using IBM SPSS ver. 21 (IBM Corp., Armonk, NY, USA).

\section{RESULTS}

According to our data, there were 625, 439, and 441 ED visits in 2010, 2011, and 2012, respectively, from the 947 pediatric patients. In all cases, the survey was conducted without any missing data.

\section{Estimation of ED visits among the population}

The numbers of pediatric ED visits among the Korean population, estimated by applying the population weights, were 1,579,783 in 2010, 1,188,056 in 2011, and 1,389,887 in 2012. Males visited more often than females, and the patient visits increased as age decreased. Disease resulted in a greater proportion of ED visits than injuries, and private cars provided most of the transportation to the ED. The most common medical service provided was emergency treatment, and $12.9 \%$ of patients were hospitalized after receiving ED services. More patients were satisfied with the ED than dissatisfied (Table 1).

\section{Satisfied vs. dissatisfied groups}

After applying the sample weights, the satisfied and dissatisfied groups contained 1,133 and 294 cases, respectively. Male patients and patients without chronic disease were more frequently found to be satisfied, whereas patients with another source of funding for medical costs were relatively less frequently satisfied. The proportion of patients who visited the ED twice or more within a year was lower in the satisfied group; this was also the case for patients hospitalized at least once during the year investigated. A greater proportion of patients transferred to another hospital after ED management were among the dissatisfied group (Appendix 1). 
Kyeong Jae Lee, et al.

Table 1. Characteristics of pediatric patients visiting the emergency department (estimates based on the population weights)

\begin{tabular}{|c|c|c|c|}
\hline Variable & & & Total \\
\hline \multirow[t]{27}{*}{ Factors related to patient characteristics } & Sex & Male & $2,421,032(58.2)$ \\
\hline & & Female & $1,736,695(41.8)$ \\
\hline & Age group & Preschool & $2,231,895(53.7)$ \\
\hline & & Elementary & $981,774(23.6)$ \\
\hline & & Middle & $452,383(10.9)$ \\
\hline & & High & $491,673(11.8)$ \\
\hline & Chronic disease & Yes & $1,192,824(28.7)$ \\
\hline & & No & $2,964,902(71.3)$ \\
\hline & Disability & Yes & $36,734(0.9)$ \\
\hline & & No & $4,120,993(99.1)$ \\
\hline & Health insurance type & $\mathrm{NHI}$ & $3,904,597(93.9)$ \\
\hline & & Medical aid & $253,130(6.1)$ \\
\hline & Source of funding other than NHI or Medical aid & Yes & $809,565(19.5)$ \\
\hline & & No & $3,344,573(80.4)$ \\
\hline & & Missing & $3,589(0.1)$ \\
\hline & Household income (quintile) & 1 & $271,316(6.5)$ \\
\hline & & 2 & $646,943(15.6)$ \\
\hline & & 3 & $1,056,371(25.4)$ \\
\hline & & 4 & $1,160,413(27.9)$ \\
\hline & & 5 & $1,019,399(24.5)$ \\
\hline & & Missing & $3,285(0.1)$ \\
\hline & No. of ED visits in 1 year & 1 & $2,408,348(57.9)$ \\
\hline & & $\geq 2$ & $1,749,379(42.1)$ \\
\hline & Hospitalization within 1 year & Yes & $1,253,723(30.2)$ \\
\hline & & No & $2,904,004(69.8)$ \\
\hline & Outpatient department visit within 1 year & Yes & $4,081,744(98.2)$ \\
\hline & & No & $75,983(1.8)$ \\
\hline \multirow[t]{28}{*}{ Factors related to the ED process } & Reason for ED visit & Injury & $1,393,626(33.5)$ \\
\hline & & Disease & $2,759,396(66.4)$ \\
\hline & & Other & $4,705(0.1)$ \\
\hline & Transportation to ED & Public ambulance & $235,595(5.7)$ \\
\hline & & Private ambulance & $16,143(0.4)$ \\
\hline & & Private car & $3,126,602(75.2)$ \\
\hline & & Taxi & $562,219(13.5)$ \\
\hline & & Walk & $172,521(4.1)$ \\
\hline & & Other & $44,646(1.1)$ \\
\hline & Transport time to ED (min) & & $15.8 \pm 12.6$ \\
\hline & Delayed ED visit & Yes & $176,129(4.2)$ \\
\hline & & No & $3,981,597(95.8)$ \\
\hline & Duration of ED stay (day) & 1 & $4,074,017(98.0)$ \\
\hline & & $\geq 2$ & $83,709(2.0)$ \\
\hline & Chief service provided & Surgery & $286,262(6.9)$ \\
\hline & & Treatment (not surgery) & $3,671,761(88.3)$ \\
\hline & & Testing only & $192,217(4.6)$ \\
\hline & & Other & $7,486(0.2)$ \\
\hline & Discharge after ED treatment & Admission & $535,864(12.9)$ \\
\hline & & Transfer to other hospital & $67,100(1.6)$ \\
\hline & & Home discharge & $3,554,762(85.5)$ \\
\hline & Amount paid & Free & $22,337(0.5)$ \\
\hline & & $\leq$ Average & $2,382,915(57.3)$ \\
\hline & & $>$ Average & $1,198,323(28.8)$ \\
\hline & & Surcharge to admission cost & $380,636(9.2)$ \\
\hline & & Car insurance & $60,223(1.4)$ \\
\hline & & Worker's compensation & $15,435(0.4)$ \\
\hline & & Other & $95,508(2.3)$ \\
\hline
\end{tabular}

(Continued to the next page) 
Table 1. Continued

\begin{tabular}{|c|c|c|c|}
\hline Variable & & & Total \\
\hline \multirow[t]{5}{*}{ Factors related to medical institution } & Hospital ownership & Public & $192,092(4.6)$ \\
\hline & & Private & $3,965,634(95.4)$ \\
\hline & & General hospital & $2,151,562(51.7)$ \\
\hline & & Hospital & $1,106,735(26.6)$ \\
\hline & & Clinic & $26,464(0.6)$ \\
\hline \multirow[t]{4}{*}{ Satisfaction } & & Very satisfied & $66,444(1.6)$ \\
\hline & & Satisfied & $3,238,804(77.9)$ \\
\hline & & Dissatisfied & $792,108(19.1)$ \\
\hline & & Very dissatisfied & $60,371(1.5)$ \\
\hline
\end{tabular}

Values are presented as number (\%) or mean \pm standard deviation.

$\mathrm{NHI}$, National Health Insurance; ED, emergency department.

Table 2. Results of the multiple logistic regression analysis investigating the associations with patient satisfaction

\begin{tabular}{|c|c|c|c|c|c|}
\hline Variable & & Unadjusted OR $(95 \% \mathrm{Cl})$ & P-value & Adjusted OR (95\% Cl) & P-value \\
\hline \multirow[t]{2}{*}{ Sex } & Male & Reference & 0.029 & Reference & 0.014 \\
\hline & Female & $0.75(0.58-0.97)$ & & $0.72(0.55-0.94)$ & \\
\hline \multirow[t]{2}{*}{ Chronic disease } & Yes & Reference & 0.004 & Reference & 0.002 \\
\hline & No & $1.49(1.13-1.95)$ & & $1.55(1.17-2.06)$ & \\
\hline \multirow{2}{*}{$\begin{array}{l}\text { Source of funding other than } \mathrm{NHI} \text { or } \\
\text { Medical aid }\end{array}$} & Yes & Reference & $<0.001$ & Reference & 0.016 \\
\hline & No & $1.71(1.27-2.30)$ & & $1.52(1.08-2.12)$ & \\
\hline \multirow[t]{2}{*}{ No. of ED visits in 1 year } & 1 & Reference & 0.014 & Reference & 0.056 \\
\hline & $\geq 2$ & $0.73(0.560-0.94)$ & & $0.76(0.58-1.01)$ & \\
\hline \multirow[t]{2}{*}{ Hospitalization within 1 year } & Yes & Reference & 0.001 & Reference & 0.040 \\
\hline & No & $1.55(1.18-2.02)$ & & $1.45(1.02-2.06)$ & \\
\hline \multirow[t]{3}{*}{ Discharge after ED treatment } & Admission & Reference & & Reference & \\
\hline & Transfer to other hospital & $0.25(0.10-0.60)$ & 0.002 & $0.24(0.08-0.74)$ & 0.013 \\
\hline & Home discharge & $1.21(0.83-1.75)$ & 0.325 & $0.74(0.33-1.67)$ & 0.465 \\
\hline \multirow[t]{7}{*}{ Amount paid } & Free & Reference & & Reference & \\
\hline & $\leq$ Average & $4.04(0.99-16.48)$ & 0.051 & $3.14(0.71-13.91)$ & 0.132 \\
\hline & $>$ Average & $3.04(0.74-12.48)$ & 0.123 & $2.50(0.56-11.13)$ & 0.230 \\
\hline & Surcharge to admission cost & $3.24(0.76-13.86)$ & 0.114 & $2.61(0.47-14.51)$ & 0.274 \\
\hline & Car insurance & $2.50(0.46-13.54)$ & 0.288 & $3.01(0.48-18.76)$ & 0.239 \\
\hline & Worker's compensation & $0.46(0.05-4.40)$ & 0.499 & $0.40(0.04-4.21)$ & 0.447 \\
\hline & Other & $1.62(0.34-7.74)$ & 0.548 & $1.55(0.28-8.49)$ & 0.613 \\
\hline
\end{tabular}

$\mathrm{OR}$, odds ratio; $\mathrm{Cl}$, confidence interval; $\mathrm{NHI}$, National Health Insurance; $\mathrm{ED}$, emergency department.

\section{Variables associated with satisfaction with ED service}

Female patients had an OR of 0.72 for satisfaction compared to the male patients. Patients without chronic disease had an OR of 1.55 compared to patients with chronic disease, and patients without another source of funding for medical costs had an OR of 1.52 compared to patients with another source. Patients who were not hospitalized during the year under evaluation had an OR of 1.45 compared to patients who were hospitalized at least once during the year. Patients who were transferred to another hospital had an OR of 0.24 compared with patients hospitalized at the same institution at which they received the ED service (Table 2).

\section{DISCUSSION}

Studies of patient satisfaction with ED services and a detailed causal analysis thereof are important for improving the emergency medical service system. Based on the results of the available research, it is possible to expect an improvement in ED services and patient satisfaction. ${ }^{18,19}$ The findings could also lead to improvements and systemic changes in the emergency medical service system. Previous studies have tried to identify factors closely related to ED patient satisfaction; however, they focused mainly on factors related to the ED service process, such as the charac- 
teristics of human resources (e.g., the kindness, attitudes, or expertise of the hospital personnel), the ED treatment process (e.g., the waiting time until doctor contact and the number of doctor contacts during the ED stay), and the ED treatment space (e.g., its cleanliness and privacy). ${ }^{14-17,20-22}$ In comparison, in the present study, we evaluated the patients' demographic and socioeconomic characteristics, as well as variables related to the medical institution.

Overall, approximately four times as many patients were satisfied than dissatisfied during the 3 years; moreover, no difference was found in the satisfaction ratings among the 3 years examined. These findings differed markedly from the results of Jang et al., ${ }^{17}$ who reported that only $40.2 \%$ of pediatric ED users were satisfied with the ED service. This discrepancy might originate from differences in the process used to select participants and the method of rating satisfaction. Whereas the patients in our survey were sampled via 2 steps of probability proportionate stratified cluster sampling and represented $90 \%$ of the national population, Jang et al. ${ }^{17}$ recruited participants with an e-mail survey and ultimately included only voluntary replies. Therefore, their work might reflect a selection bias. Further, although we asked only a single question to rate patient satisfaction with the ED service, Jang et al. ${ }^{17}$ additionally investigated satisfaction with various ED service components. We consider that this level of scrutiny may have influenced the participants to retrieve negative memories of their ED service, which may have resulted in the relatively low levels of satisfaction. Unlike in the research conducted by Jang et al., ${ }^{17}$ in which the patients' parents rated the satisfaction in all cases, in our study, 2.3\% of the pediatric participants rated their own satisfaction. However, we do not believe that this was the main reason for the difference in satisfaction, because this proportion was very small.

Our analysis found significant associations between the following variables and satisfaction with ED services: sex, chronic disease, another financial source of funds for medical costs, number of annual ED visits, hospitalization experience within 1 year (patient characteristics), and discharge after ED treatment (ED service process characteristic). Patients with chronic disease, those with 2 or more ED visits in 1 year, and those who were hospitalized at least once during the year under examination had lower ORs for satisfaction. Although the exact cause of these findings is unclear, one possible explanation is that these patients were more prone than others to use medical services, thus increasing their average expectation regarding satisfaction with the ED service. Additionally, patients with an alternate source of payment for their medical costs, such as car insurance, worker's compensation, or private medical insurance, were relatively dissatisfied. We speculate that their expectations for wide warranty coverage and high service quality might have played a major role in accounting for this finding.

Regarding discharge after ED treatment, the odds of satisfaction among patients who were transferred to another hospital after ED treatment was 0.24 times lower than those among patients who were hospitalized at the same hospital in which they visited the ED. We believe that transfer negatively affected patient satisfaction because the majority of patients were transferred to another hospital when further evaluation or management was impossible in the hospital housing the ED or when their confidence in the hospital was lower.

Lee et al. ${ }^{23}$ investigated the satisfaction of patients of all ages with ED services using the 2010 KHPD; however, these authors did not evaluate a pediatric subgroup. They reported that the reason for the ED visit (disease or injury), transportation method, and delay in ED arrival were all associated with patient satisfaction, whereas these factors were not associated with patient satisfaction in our analysis. We consider that this discrepancy might have been caused by differences in the peak visit date and time, severity and types of disease or injury, and types and range of ED services provided to adult patients. Previous studies have indicated that pediatric patients usually visit the ED when a primary clinic is not available, ${ }_{1}^{21}$ and about one-third of pediatric patients visit the ED for the purpose of simple observation and treatment of a simple disease. ${ }^{5}$

This study has several limitations. First, information drawn from a cross-sectional survey might involve recall bias because of the time gap between the survey and ED visit (maximum of 1 year in most cases). Second, we did not consider unmeasured confounders relevant to satisfaction, such as severity of illness, date or time of ED visit, time spent during the ED process (e.g., the waiting time before meeting the doctor or the actual duration [in hours] of the ED stay), kindness or specialty of medical personnel, quality of medical equipment and facilities, or atmosphere of the treatment space. Third, the gap between the satisfaction levels reported by parents and patients was not investigated. This might be helpful for a more detailed analysis of various factors associated with patient satisfaction; thus, such an investigation is warranted in the future. Despite these limitations, this study is important in that the data were drawn from representative samples, and this study also evaluated patient and institutional factors potentially related to the ED service process.

In summary, sex, presence of chronic disease, presence of financial funding other than NHI, hospitalization within the year, 2 or more ED visits in a year, and discharge after ED treatment were associated with patient satisfaction in our analysis. Future pro- 
spective studies should evaluate the causal relationships between the relevant factors and patient satisfaction with ED services. Adjustment of such relevant factors may improve the pediatric emergency medical system.

\section{CONFLICT OF INTEREST}

No potential conflict of interest relevant to this article was reported.

\section{REFERENCES}

1. Stuart PJ, Parker S, Rogers M. Giving a voice to the community: a qualitative study of consumer expectations for the emergency department. Emerg Med (Fremantle) 2003;15:369-75.

2. National Emergency Medical Center. 2014 Emergency medical service statics annual report. Seoul: National Emergency Medical Center; 2015.

3. Kwak YH, Kim DK, Jang HY. Utilization of emergency department by children in Korea. J Korean Med Sci 2012;27:1222-8.

4. Kim DK, Kwak YH, Lee SJ, et al. A national survey of current practice patterns and preparedness of pediatric emergency care in Korea. J Korean Soc Emerg Med 2012;23:126-31.

5. Scribano PV, Wiley JF 2nd, Platt K. Use of an observation unit by a pediatric emergency department for common pediatric illnesses. Pediatr Emerg Care 2001;17:321-3.

6. Gausche-Hill M, Schmitz C, Lewis RJ. Pediatric preparedness of US emergency departments: a 2003 survey. Pediatrics 2007; 120:1229-37.

7. McGillivray D, Nijssen-Jordan C, Kramer MS, Yang H, Platt R. Critical pediatric equipment availability in Canadian hospital emergency departments. Ann Emerg Med 2001;37:371-6.

8. Salter R, Maconochie IK. Implementation of recommendations for the care of children in UK emergency departments: national postal questionnaire survey. BMJ 2005;330:73-4.

9. Yarnold PR, Michelson EA, Thompson DA, Adams SL. Predicting patient satisfaction: a study of two emergency departments. J Behav Med 1998;21:545-63.

10. Rydman RJ, Roberts RR, Albrecht GL, Zalenski RJ, McDermott M. Patient satisfaction with an emergency department asthma observation unit. Acad Emerg Med 1999;6:178-83.

11. Hostutler JJ, Taft SH, Snyder C. Patient needs in the emergen- cy department: nurses' and patients' perceptions. J Nurs Adm 1999;29:43-50.

12. Shefrin $A E_{1}$ Milner $R$, Goldman RD. Adolescent satisfaction in an urban pediatric emergency department. Pediatr Emerg Care 2012;28:633-9.

13. Johnson MB, Castillo EM, Harley J, Guss DA. Impact of patient and family communication in a pediatric emergency department on likelihood to recommend. Pediatr Emerg Care 2012; 28:243-6.

14. Pagnamenta $R$, Benger JR. Factors influencing parent satisfaction in a children's emergency department: prospective questionnaire-based study. Emerg Med J 2008;25:417-9.

15. Magaret ND, Clark TA, Warden CR, Magnusson AR, Hedges JR. Patient satisfaction in the emergency department: a survey of pediatric patients and their parents. Acad Emerg Med 2002;9: 1379-88.

16. Moon SY, Kim SJ. The degree of satisfaction with nursing care of pediatric patients visiting emergency center. Korean J Child Health Nurs 2000;6:5-17.

17. Jang HY, Kwak YH, Park JO, Kim DK, Lee JH. Parental satisfaction with pediatric emergency care: a nationwide, cross-sectional survey in Korea. Korean J Pediatr 2015;58:466-71.

18. Taylor D, Kennedy MP, Virtue E, McDonald G. A multifaceted intervention improves patient satisfaction and perceptions of emergency department care. Int J Qual Health Care 2006;18: 238-45.

19. Ziniel SI, Connor JA, Graham D, et al. Development and psychometric characteristics of the pediatric inpatient experience survey (PIES). Int J Qual Health Care 2016;28:191-9.

20. Soleimanpour H, Gholipouri C, Salarilak S, et al. Emergency department patient satisfaction survey in Imam Reza Hospital, Tabriz, Iran. Int J Emerg Med 2011;4:2.

21. Brown AD, Sandoval GA, Levinton C, Blackstien-Hirsch P. Developing an efficient model to select emergency department patient satisfaction improvement strategies. Ann Emerg Med 2005;46:3-10.

22. Lee SJ, Cho YD, Park SJ, Kim JY, Yoon YH, Choi SH. Satisfaction with facial laceration repair by provider specialty in the emergency department. Clin Exp Emerg Med 2015;2:179-83.

23. Lee JC, Kim KH, Kim HN, Park YH. Patient satisfaction with emergency medical services in Korea: what matters most? J Korean Soc Emerg Med 2011;22:299-308. 
Kyeong Jae Lee, et al.

Appendix 1. Comparisons of satisfied and dissatisfied groups (estimates based on the sample weights)

\begin{tabular}{|c|c|c|c|c|}
\hline Variable & & Dissatisfied $(n=294)$ & Satisfied $(n=1,133)$ & P-value \\
\hline \multirow[t]{2}{*}{ Sex } & Male & $155(52.7)$ & $678(59.8)$ & 0.028 \\
\hline & Female & $139(47.3)$ & $456(40.2)$ & \\
\hline \multirow[t]{4}{*}{ Age group } & Pre-school & $157(53.3)$ & $607(53.6)$ & 0.629 \\
\hline & Elementary school & $76(25.9)$ & $263(23.2)$ & \\
\hline & Middle school & $27(9.1)$ & $129(11.4)$ & \\
\hline & High school & $34(11.7)$ & $134(11.9)$ & \\
\hline \multirow[t]{2}{*}{ Chronic disease } & Yes & $104(35.4)$ & $306(26.9)$ & 0.006 \\
\hline & No & $190(64.6)$ & $828(72.1)$ & \\
\hline \multirow[t]{2}{*}{ Disability } & Yes & $3(1.0)$ & $10(0.9)$ & 0.824 \\
\hline & No & 291 (99.0) & $1,124(99.1)$ & \\
\hline \multirow[t]{2}{*}{ Health insurance type } & $\mathrm{NHI}$ & 276 (93.8) & $1,065(94.0)$ & 0.938 \\
\hline & Medical aid & $18(6.2)$ & $68(6.0)$ & \\
\hline \multirow{3}{*}{$\begin{array}{l}\text { Source of funding other than } \mathrm{NHI} \text { or } \\
\text { Medical aid }\end{array}$} & Yes & 79 (27.0) & $201(17.8)$ & 0.002 \\
\hline & No & $215(73.0)$ & $931(82.1)$ & \\
\hline & Missing & & $1(0.1)$ & \\
\hline \multirow[t]{6}{*}{ Household income (quintile) } & 1 & $17(5.8)$ & $76(6.7)$ & 0.744 \\
\hline & 2 & 40 (13.5) & $183(16.1)$ & \\
\hline & 3 & $82(28.0)$ & $279(24.6)$ & \\
\hline & 4 & $85(28.9)$ & $314(27.7)$ & \\
\hline & 5 & $70(23.8)$ & $280(24.7)$ & \\
\hline & Missing & & $1(0.1)$ & \\
\hline \multirow[t]{2}{*}{ No. of ED visits in 1 year } & 1 & $152(51.7)$ & $676(59.6)$ & 0.017 \\
\hline & $\geq 2$ & $142(48.3)$ & $258(40.4)$ & \\
\hline \multirow[t]{2}{*}{ Hospitalization within 1 year } & Yes & $111(37.9)$ & $320(28.3)$ & 0.002 \\
\hline & No & $183(62.1)$ & $813(71.7)$ & \\
\hline \multirow[t]{2}{*}{ Outpatient department visit within 1 year } & Yes & $288(97.9)$ & $1,114(98.3)$ & 0.751 \\
\hline & No & $6(2.1)$ & $20(1.7)$ & \\
\hline \multirow[t]{2}{*}{ Respondent } & Self & $7(2.3)$ & $25(2.2)$ & 0.857 \\
\hline & Guardian & $287(97.7)$ & $1,108(97.8)$ & \\
\hline \multirow[t]{3}{*}{ Reason for ED visit } & Injury & $89(30.3)$ & $389(34.3)$ & 0.257 \\
\hline & Disease & $204(69.5)$ & $743(65.6)$ & \\
\hline & Other & $1(0.3)$ & $1(0.1)$ & \\
\hline \multirow[t]{2}{*}{ Transportation to ED } & Ambulance & $20(1.4)$ & $67(4.7)$ & 0.584 \\
\hline & The others & $274(19.2)$ & $1,066(74.7)$ & \\
\hline Transport time to ED (min) & & $17.0 \pm 13.0$ & $15.5 \pm 12.5$ & 0.059 \\
\hline \multirow[t]{2}{*}{ Duration of ED stay (day) } & 1 & $288(97.8)$ & $1,111(98.0)$ & 0.989 \\
\hline & $\geq 2$ & $6(2.2)$ & $23(2.0)$ & \\
\hline \multirow[t]{4}{*}{ Chief service, provided } & Surgery & $28(8.8)$ & $71(6.3)$ & 0.078 \\
\hline & Treatment (not surgery) & $260(88.6)$ & $1,000(88.3)$ & \\
\hline & Test only & $7(2.2)$ & $60(5.3)$ & \\
\hline & Other & $1(0.3)$ & $2(0.1)$ & \\
\hline \multirow[t]{3}{*}{ Discharge after ED treatment } & Admission & $42(14.3)$ & $143(12.6)$ & $<0.001$ \\
\hline & Transfer to other hospital & $13(4.3)$ & $11(0.9)$ & \\
\hline & Home discharge & $239(81.4)$ & $980(86.4)$ & \\
\hline \multirow[t]{2}{*}{ Delay in ED visit } & Yes & $16(5.4)$ & $45(4.0)$ & 0.267 \\
\hline & No & $278(94.6)$ & $1,088(96.0)$ & \\
\hline
\end{tabular}

(Continued to the next page) 
Appendix 1. Continued

\begin{tabular}{|c|c|c|c|c|}
\hline Variable & & Dissatisfied $(n=294)$ & Satisfied $(n=1,133)$ & P-value \\
\hline \multirow[t]{8}{*}{ Amount paid } & Free & $4(1.3)$ & $4(0.4)$ & 0.001 \\
\hline & $\leq$ Average & $148(50.3)$ & $670(59.1)$ & \\
\hline & > Average & $93(31.7)$ & $317(28.0)$ & \\
\hline & Surcharge to admission cost & $28(9.6)$ & $102(9.0)$ & \\
\hline & Car insurance & $6(1.9)$ & $16(1.4)$ & \\
\hline & Worker's compensation & $4(1.2)$ & $2(0.2)$ & \\
\hline & Other & $12(4.0)$ & $21(1.9)$ & \\
\hline & Missing & & $1(0.1)$ & \\
\hline \multirow[t]{2}{*}{ Hospital ownership } & Public & $11(3.9)$ & $54(4.8)$ & 0.459 \\
\hline & Private & $282(96.1)$ & $1,079(95.2)$ & \\
\hline \multirow[t]{5}{*}{ Hospital level } & General hospital (senior) & $77(26.1)$ & 215 (19.0) & 0.053 \\
\hline & General hospital & $149(50.8)$ & $588(51.9)$ & \\
\hline & Hospital & $66(22.5)$ & $313(27.7)$ & \\
\hline & Clinic & $1(0.3)$ & $8(0.7)$ & \\
\hline & Other & $1(0.3)$ & $8(0.7)$ & \\
\hline
\end{tabular}

Values are presented as number (\%) or mean \pm standard deviation.

$\mathrm{NHI}$, National Health Insurance; ED, emergency department. 